\title{
Two Potato Proteins, Including a Novel RING Finger Protein (HIP1), Interact with the Potyviral Multifunctional Protein HCpro
}

\author{
Deyin Guo, ${ }^{1,}{ }^{4}$ Carl Spetz, ${ }^{2}$ Mart Saarma, ${ }^{1}$ and Jari P. T. Valkonen ${ }^{2,3}$ \\ ${ }^{1}$ Institute of Biotechnology, PO Box 56, Viikki Biocenter, FIN-00014 University of Helsinki, Finland; ${ }^{2}$ Department of Plant \\ Biology, Genetics Centre, SLU, SE-750 07 Uppsala, Sweden; ${ }^{3}$ Department of Applied Biology, PO Box 27, FIN-00014 \\ University of Helsinki, Finland; ${ }^{4}$ College of Life Sciences, Modern Virology Center, Wuhan University, Wuhan 430072, China.
}

Submitted 23 September 2002. Accepted 11 December 2002.

Potyviral helper-component proteinase (HCpro) is a multifunctional protein exerting its cellular functions in interaction with putative host proteins. In this study, cellular protein partners of the HCpro encoded by Potato virus $A$ (PVA) (genus Potyvirus) were screened in a potato leaf cDNA library using a yeast two-hybrid system. Two cellular proteins were obtained that interact specifically with PVA HCpro in yeast and in the two in vitro binding assays used. Both proteins are encoded by single-copy genes in the potato genome. Analysis of the deduced amino acid sequences revealed that one (HIP1) of the two HCpro interactors is a novel RING finger protein. The sequence of the other protein (HIP2) showed no resemblance to the protein sequences available from databanks and has known biological functions.

Potyviruses (genus Potyvirus, family Potyviridae) comprise the largest and the economically most important group of plant viruses, causing yield losses and reduction of quality in all major crops worldwide (Shukla et al. 1994). They form flexuous, rod-shaped particles that contain a single-stranded, positivesense RNA genome of about 10 kilobases $(\mathrm{kb})$. The genomic RNA is translated to a large polyprotein that is subsequently processed by three virus-encoded proteinases to yield about ten mature proteins (Riechmann et al. 1992).

The potyviral helper component-proteinase (HCpro) is a multifunctional protein (Maia et al. 1996). It is involved in autoproteolytic cleavage of its C-terminus from the polyprotein (Carrington et al. 1989), RNA binding (Maia and Bernardi 1996; Merits et al. 1998), genome replication and symptom expression (Atreya and Pirone 1993; Dolja et al. 1993; Kasschau and Carrington 1995), aphid transmission (Pirone and Blanc 1996), virus movement in plants (Cronin et al. 1995; Kasschau et al. 1997; Rojas et al. 1997), and trans-activation of replication of other viruses (Pruss et al. 1997; Shi et al. 1997). More recently, HCpro has been shown to be a viral suppressor of RNA silencing and to act as a general virulence enhancer (Anandalakshmi et al. 1998; Brigneti et al. 1998; Kasschau and Carrington 1998; Yelina et al. 2002).

Knowledge about host proteins interacting with potyviral HCpro will help to elucidate the molecular mechanisms of its

Corresponding authors: D. Guo; Telephone: +86-27-87876506; Fax: +86-27-87869897; E-mail: dguo@whu.edu.cn; or J. P. T. Valkonen; Telephone: +358-9-19158387; Fax: +358-9-19158727; E-mail: jari.valkonen@helsinki.fi. multiple functions. Anandalakshmi and associates (2000) showed that a calmodulin-related protein can interact with the HCpro of Tobacco etch virus (TEV) (genus Potyvirus), but it can suppress gene silencing independent of the interaction with HCpro. Additional protein-protein interactions are conceivably involved in mediating the multiple functions of HCpro. In this study, we used the HCpro of Potato virus A (PVA) (genus Potyvirus) as a bait to screen for interacting proteins of its natural host, potato (Solanum tuberosum L.), in a yeast twohybrid system (YTHS). Our results show that one of the interacting proteins (designated as HIP1 for HCpro Interacting Protein 1) is a novel RING finger protein belonging to a large family of regulatory proteins conserved throughout the plant, animal, fungal, and protozoa kingdoms.

\section{RESULTS}

Screening for HIP with the YTHS.

The full-length PVA HCpro fused with the LexA DNA-binding domain (pLexA-Hcpro, Trp+) was used as a bait to screen a potato leaf cDNA library (Sorri et al. 1999) fused to the Gal4 activation domain (pAD-GAL4, Leu+) in yeast cells. About 1 $\times 10^{7}$ transformants (Trp+,Leu+) obtained by the screening were plated directly onto selection medium lacking Trp, Leu, and His, and 54 colonies were recovered following the selection. Secondary screening based on a blue and white selection by filter assays identified 20 colonies that were positive for the $\beta$-galactosidase activity. The cDNA plasmids of these 20 colonies were purified and retransformed into yeast strain L40 together with pLexA-HCpro or empty pLexA vector (as a negative control) to test the specificity or prey protein-dependent $\beta$ galactosidase activity. With the purified plasmids, two clones displayed specific and strong interactions with PVA HCpro in yeast (Fig. 1A) and were designated as HIP1 and HIP2. The coat protein (CP) of PVA and human lamin were used as negative controls, and the results were similar to the empty vectors (data not shown).

The original clones of HIP1 and HIP2 from the potato cDNA library were sequenced. They were $1.75 \mathrm{~kb}$ and $1.7 \mathrm{~kb}$ in size, respectively, containing 21 and 34 adenines at the $3^{\prime}$ end. Thus, they represented the $3^{\prime}$ parts of the mRNAs. Subsequently, sequencing of the vector-gene junctions confirmed that the open reading frames of HIP1 and HIP2 were in-frame at the activation domains in the yeast vectors. The missing $5^{\prime}$ parts of HIP1 and HIP2 were polymerase chain reaction (PCR)-amplified from a potato Marathon cDNA library constructed for this purpose (discussed below). The longest PCR clones expected to 
contain the $5^{\prime}$ ends were sequenced. Using the sequence information of both yeast clones and PCR-amplified $5^{\prime}$ clones, the full-length cDNAs of HIP1 (2,231 bp) and HIP2 (3,040 bp) were amplified by PCR from the Marathon cDNA library and were sequenced. The sequences of original yeast clones were identical to the $3^{\prime}$ part of the PCR-amplified full-length clones. The HIP1 and HIP2 sequences have been deposited in the EMBL database under accession numbers AJ507316 and AJ507317, respectively.

Since a large part of HIP2 was not included in the original clone detected based on its interaction with HCpro in YTHS, the full-length Hip2 gene was cloned to the yeast vectors and was tested for interactions with HCpro. Results of the $\beta$-galactosidase assay (data not shown) were similar to those obtained with the original clone, indicating that the $3^{\prime}$ proximal part of HIP2 is sufficient for the interaction with HCpro.

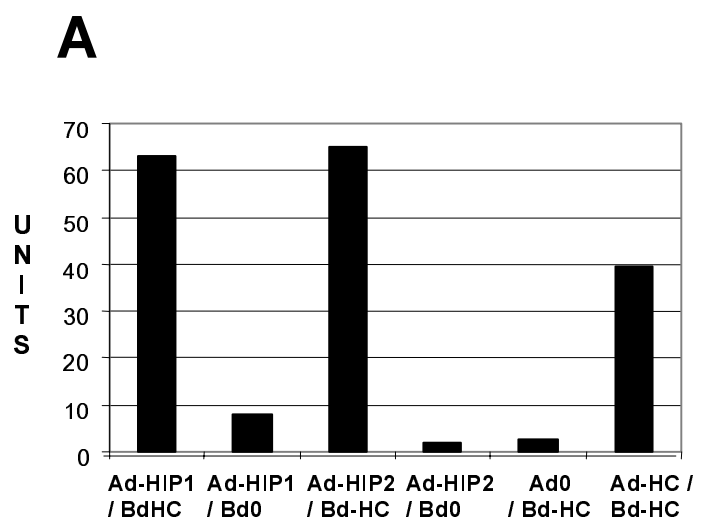

B

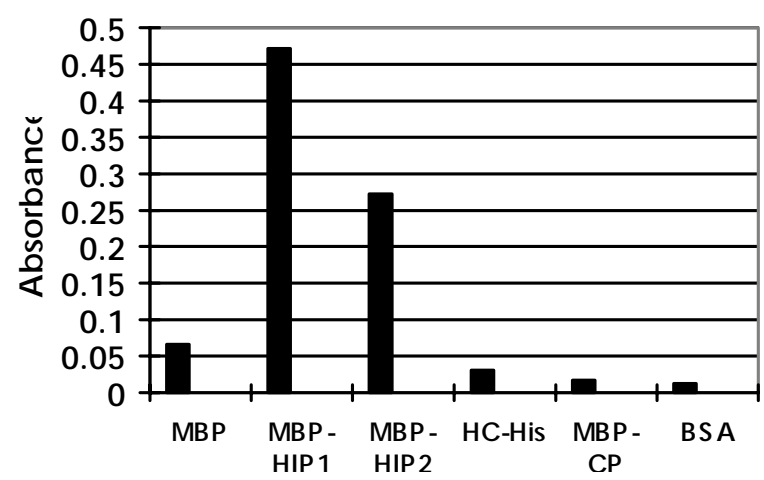

Fig. 1. Interactions of the potyviral helper-component proteinase (HCpro) of Potato virus A (PVA) and the potato proteins HIP1 and HIP2 in yeast cells and in vitro, as detected by an overlay enzyme-linked immunosorbent assay (ELISA). A, Relative interaction strengths between HCpro and the HIP proteins in $\beta$-galactosidase assays using liquid culture. The relative units are used to indicate the interaction. Ad indicates the GAL4 activation domain and Bd indicates the LexA DNAbinding domain. Ad0 and Bd0 indicate "empty" vector plasmids that gave rise to results similar to the human lamin protein expressed as an Ad and $\mathrm{Bd}$ fusion protein and used as an additional negative control (not shown). AdHC/BdHC indicates the self-interaction of HCpro that was used as a positive control (Guo et al. 1999). B, Overlay ELISA. The plate was coated with 6xHis-tagged HCpro. Polyclonal antibodies to the maltose-binding protein (MBP) were used to detect binding of the HIP proteins fused to MBP. The negative controls included MBP, 6xHistagged HCpro, MBP fused to the coat protein of PVA (MBP-CP), and bovine serum albumin (BSA). The interaction strength is indicated by an absorbance value measured by an ELISA reader.
HIP1 and HIP2 interact with PVA HCpro

in vitro (pull-down assay and

overlay enzyme-linked immunosorbent assays [ELISA]).

To confirm the interactions between PVA HCpro, the two selected potato proteins HIP1 and HIP2 were expressed in Escherichia coli in fusion with a maltose-binding protein (MBP). For the overlay ELISA, the plate was coated with the 6xHis-tagged HCpro (no MBP fusion) (Merits et al. 1999) and subsequently overlaid with MBP fusion proteins. The proteinbinding was detected using antibodies to MBP. As shown in Figure 1B, MBP-HIP1 and MBP-HIP2 bind to HCpro, showing significantly elevated absorbance values at least 10 times greater than the controls (MBP and MBP-CP) (Merits et al. 1999). Furthermore, the 6xHis-tagged HCpro and bovine serum albumin (BSA) were tested as a control, and the results were negative. Thus, the results indicated that the binding detected by the overlay ELISA was mediated by the HIP1 and HIP2 domains in the protein fusions.

A pull-down assay was carried out as a third type of test for the interaction between HCpro and the HIP proteins. As shown in Figure 2, when similar amounts of MBP fusion proteins were mixed with in vitro-translated and radioactively labeled HCpro, the HCpro could be coprecipitated with MBP-HIP1 and MBP-HIP2 (Fig. 2, lanes 6 and 7) but not MBP (Fig. 2, lane 8), using MBP-binding amylose resin. Based on comparison of the amounts of proteins used in the assays (Fig. 2, lanes 2 and 3 ) and the signals detected in the pull-down assay (Fig. 2, lanes 6 and 7), it seems that the pull-down assay reveals a stronger interaction between HIP1 and HCpro than what is observed with HIP2.

Taken together, the in vitro binding assays confirmed the specific interactions between the PVA HCpro and the potato proteins HIP1 and HIP2.

\section{HIP1 is a novel RING finger protein.}

The deduced amino acid sequences of HIP1 and HIP2 are shown in Figure 3A and B, respectively. Sequence analysis of the cDNA clones revealed that Hipl encodes a novel RING finger protein (HIP1) (Fig. 3A). Hip2 codes for an unknown protein (HIP2) (Fig. 3B) in which no significant functional motifs can be predicted based on comparison with previously described protein sequences available in sequence databanks.

The sequence of HIP1 was further analyzed for its modular organization. The full-length cDNA is predicted to encode a protein of 508 amino acids with an N-terminal ATP/GTP binding site motif (Kjeldgaard et al. 1996) followed by a RING finger domain (Freemont 2000) (Fig. 3A). The RING finger is a cysteine-rich zinc-binding domain, and the canonical $\mathrm{C}_{3} \mathrm{HC}_{4}$ type is defined by the consensus sequence motif with conserved cysteine and histidine residues: $C-X_{2}-C-X_{(9-39)}-C-X_{(1-3)^{-}}$ $\mathrm{H}-\mathrm{X}_{(2-3)}-\mathrm{C}-\mathrm{X}_{2}-\mathrm{C}-\mathrm{X}_{(4-48)}-\mathrm{C}-\mathrm{X}_{2}-\mathrm{C}$ (where $\mathrm{X}$ can be any amino acid) (Freemont 2000). The RING finger motif of HIP1 is $\mathrm{C} 3 \mathrm{H} 2 \mathrm{C} 3$, i.e., a RING-H2 variant with the fourth cysteine of the classical RING finger replaced by a histidine, which is common in plants (Jensen et al. 1998). The N-terminal RING finger domain of HIP1 is followed by an extended putative coiled-coil region (Fig. 3A). The coiled-coil region can be further divided into three coiled-coil domains, of which the two $\mathrm{N}$-proximal domains (residues 90 to 145 and 173 to 190 ) may form leucine zipper-like coils (Landschulz et al. 1988). The putative coiled-coil region of HIP1 (residues 92 to 245) is similar to the rod-like tails of myosin-heavy chains in periodic charge distributions (McLachlan and Karn 1982). The amphipathic structure of the coiled-coil domain indicates that it can interact with another helix. Protein analysis did not reveal any known structural motif in the C-proximal half of HIP1. The primary sequence and modular structure of the N-terminal half of HIP1 
shares significant similarity $(P<0.001$ according to the statistics of Karlin and Altschul [1990]) to the animal TRAF-interacting protein (TRIP) that inhibits TRAF2-mediated NF- $\kappa, B$ activation (Lee et al. 1997).

\section{Hip1 and Hip2 are single-copy genes in potato.}

The copy numbers of the two novel genes Hipl and Hip2 were determined by Southern blot analysis, under stringent conditions. The sequence analysis revealed that Hipl cDNA contains an EcoRI restriction site and a HindIII site, three $\mathrm{XbaI}$ sites, but no sites for EcoRV, ApaI, SacI, and KpnI. Digestion of potato genomic DNA with HindIII resulted in two bands and with $X b a \mathrm{I}$ in four bands, whereas digestion with EcoRV, ApaI, $S a c$ I, or KpnI resulted in only a single band when the fulllength Hip 1 cDNA was used as probe (Fig. 4A). The EcoRI site is located in the very beginning of the Hip 1 cDNA sequence. Therefore, a single band was revealed when the genomic DNA was digested with EcoRI. Taken together, the Southern blot analyses indicated that Hip 1 is a single copy gene. A few additional weak bands could be observed in the Hip 1 blot (Fig. 4A), indicating that closely related genes sharing some degree of sequence similarity with Hipl may exist in the potato genome.

The same set of restriction enzymes was used for Southern blot analysis of Hip2. The Hip2 cDNA sequence contains a single ApaI site but no sites for EcoRV, XbaI, SacI, and KpnI. Digestion with ApaI resulted in two bands, whereas digestion with EcoRV, XbaI, SacI, or KpnI gave rise to a single band when the full-length Hip 2 cDNA was used as probe (Fig. 4B). These data indicated that Hip2 also is a single copy gene. There are four EcoRI and four HindIII sites in the Hip2 cDNA sequence. Digestion with EcoRI and HindIII generated six and three bands, respectively (Fig. 4B), in contrast with the expectation of five bands. The result of EcoRI digestion may be explained with an additional EcoRI site possibly residing in an intron of the Hip2 gene. For HindIII digestion, two of the HindIII sites are located very closely to each other (48 bp apart), so that the resulting 48-bp band could not be resolved in the blot. In addition, two fragments generated by HindIII may be of similar size and thus not separated. This may explain why only 3 bands were observed for the Hip2 gene following HindIII digestion.

\section{DISCUSSION}

The potyviral HCpro is a multifunctional protein (Maia et al. 1996) that may require interactions with a number of cellular proteins to exert the different functions. Our data show that HIP1 and HIP2 interact with HCpro in three independent assays, and these novel interactions may help to elucidate some of the multiple biological functions of potyviral HCpro. Only one other host protein has been reported to interact with the potyviral HCpro. A calmodulin-related protein that can suppress RNA silencing, a cellular antiviral defense mechanism (Ratcliff et al. 1997; Yelina et al. 2002), interacts with the HCpro of TEV, but the interaction is dispensable for the RNA silencing activity (Anandalakshmi et al. 2000). Thus, the functional significance of the interaction between the calmodulinlike protein and HCpro awaits further clarification.

In this study, a novel RING finger protein was described and was shown to interact with HCpro. Proteins with a RING finger motif are known in viruses and all taxa of eukaryotic organisms across the kingdoms (Saurin et al. 1996). The RING finger domain is often involved in protein-protein interactions and in formation of multiprotein complexes. The RING finger domain is outside (upstream) the original clone of HIP1 that was used to reveal the HIP1-HCpro interaction and is, there- fore, not required for direct interaction with HCpro, but it may be involved in interactions with other proteins to form a putative protein complex involving HIP1 and HCpro. Previous studies have shown that the RING finger-containing proteins have diverse cellular functions involved in viral infectivity and virulence, oncogenesis, signal transduction, peroxisome biogenesis, DNA repair and recombination, and membrane vesicle sorting (Saurin et al. 1996; Freemont 2000).

Recent studies have shown that many RING finger-containing proteins may act as E3 ubiquitin protein ligases and the RING finger can specifically interact with E2 ubiquitin-conjugating enzymes, thereby promoting ubiquitination of target proteins (Freemont 2000). It is hypothesized that HIP1 may promote the ubiquitination and subsequent degradation of the viral protein HCpro, a potent suppressor of RNA silencing, which in turn may help to prevent the HCpro-mediated counter-defense of potyviruses (Anandalakshmi et al. 1998; Brigneti et al. 1998; Kasschau and Carrington 1998; Yelina et al. 2002). Attempts to test this hypothesis by overexpressing HIP1 from a Potato virus $X$-derived vector in HCpro transgenic plants (Savenkov and Valkonen 2001, 2002) and monitoring changes of HCpro accumulation were hampered due to instability of Hipl cDNA in the vector (data not shown). Also, Hipl and Hip2 are apparently expressed to low levels, and the mRNA could not be detected in healthy or PVA-infected potato plants by Northern blot analysis (data not shown), which hampered studies on their putative functions during PVA infection. Transgenic plants overexpressing or silenced for Hipl and Hip2 expression will be required to reveal the functions of Hipl and Hip2.

\section{MATERIALS AND METHODS}

Strains and plasmids.

The yeast strain L40 (MATa, his34200, trp1-901, leu2-3,112, ade2, lys2-801am, URA3::[lexAop] $]_{8}$ lacZ, LYS2::[lexAop] $4^{-}$ HIS3) and plasmid pBTM116 have been described (Hollenberg
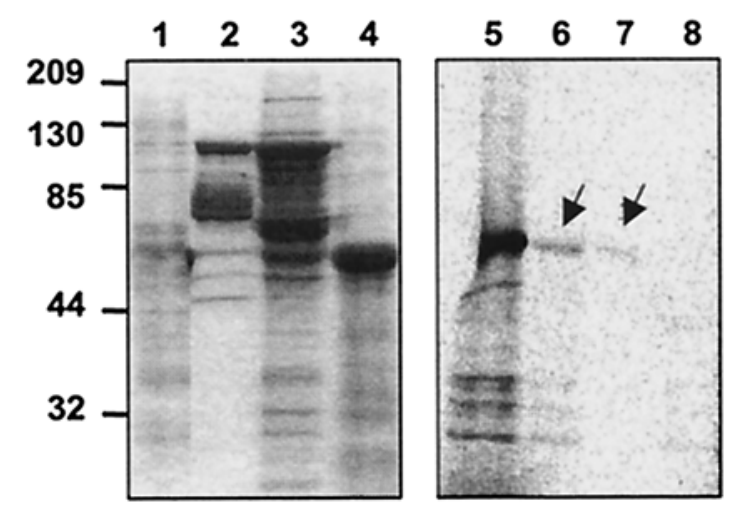

Fig. 2. Pull-down assays reveal interactions between the potyviral helpercomponent proteinase (HCpro) of Potato virus $A$ and the potato proteins HIP1 and HIP2. The maltose-binding protein (MBP) and MBP fusions with HIP1 and HIP2 were expressed in Escherichia coli, and total soluble proteins of the E. coli cells were used in the binding assays. HCpro was translated in vitro and radiolabeled. Lanes 1 to 4 show the proteins used for the binding assay, separated on sodium dodecyl sulphate polyacrylamide gel electrophoresis (SDS-PAGE) and stained with Coomassie blue. Lanes 5 to 8 show the radioautography of proteins precipitated from the mixture of radiolabeled HCpro and MBP-HIP by MBP-binding amylose resin and subsequently separated by SDS-PAGE. Lanes 1 and 5 contain $5 \mu \mathrm{l}$ of an in vitro translation mixture of HCpro used for binding assay. Lanes 2 to 4 contain total cellular proteins of $E$. coli cells expressing recombinant MBPHIP1, MBP-HIP2, and MBP, respectively. Lanes 6 to 8 represent binding combinations of radiolabeled HCpro with MBP-HIP1, MBP-HIP2, and MBP that was included as a negative control, respectively. The arrowheads show the bands corresponding to the HCpro coprecipitated with MBPbinding amylose resin. 
et al. 1995). The DNA-binding domain vector $\mathrm{pLexNa}$ is derived from pBTM116 by inserting the $A D E 2$ gene into the $P v u I I$ site and an SV40 large T antigen nuclear localization signal immediately $\mathrm{N}$-terminal to the polylinker. The yeast vector pACT2 (Clontech, Palo Alto, CA, U.S.A.) contains an GAL4 activation domain.

The cDNA sequence coding for HCpro was cloned from the full-length cDNA of PVA strain B11 (Puurand et al. 1996) by polymerase chain reaction (PCR), using appropriate primers and an expand high-fidelity DNA polymerase (Boehringer Mannheim, Mannheim, Germany). The cloning strategies have been described (Guo et al. 1999). All the PCR clones and the fusion junctions in the YTHS vectors were verified by sequencing, using standard methods.

\section{Potato cDNA library construction.}

Potato clone V2-62 (Hämäläinen et al. 2000) was inoculated with PVA, and inoculated leaves were collected ten days after inoculation. Total RNA was prepared according to Verwoerd and associates (1989), and mRNA was isolated with Oligotex mRNA kit (Qiagen, Hilden, Germany). mRNA ( $5 \mu \mathrm{g})$ was used for cDNA synthesis, using the HybriZAP II two-hybrid system kit (Stratagene, La Jolla, CA, U.S.A.), and cDNAs larger than 500 bp were inserted into lamda HybriZAP II two-hybrid vector as EcoRI-XhoI fragments, according to standard protocols. The primary $\lambda$ phage library contained about $2 \times 10^{6}$ independent clones and was converted to a pAD-GAL4 activation plasmid library by in vivo mass excision, according to manufacturer's instructions.

For cloning the missing $5^{\prime}$ ends of the mRNAs, a Marathon (Clontech) cDNA library was prepared with the mRNAs extracted from potato plants, according to Clontech's protocols. The 5' sequences were amplified directly from the cDNA library by PCR with appropriate primers.

\section{Yeast two-hybrid assay and cDNA library screening.}

The yeast two-hybrid assays were carried out essentially as described by Hollenberg and associates (1995). Yeast transfor-

A

1 MVGVNSFGKT ICS ICYEDLN PIIEDLQAVT ICGHVFHELC LQQWFEYCAK

51 GKKKNCPVCK QACSEENANR IYFQSIGDPN FTSLTQKPPD YKEDHRELKN

101 EVKRLERKVV GLTSTLEKQL KDLKDVNAEL FTCKEELKME MTLKIEAVKQ

151 EAAIQQLLHL KSKELDQSTL ECIRIQDRNM ALAKELATLK LVCDFNLEEE

201 EVLKRASLRD DVNSKETIDV LKKSLVIRNK NYEELMTKCN TLDRREVRYL

251 RKLQKTKEKK NKLKARVQEL EMALEGKDNE ILRILKASKK NYQGSKEPKV

301 DRCSYENQNK APAETEVDVC IVTGSCDDLS RPKRKRKYKS KDKSIPNMAE

351 DIIASTLHKN NHEKESSKRN KDGGTPETSS YVHEGSYQNL HQPFDHKKAV

401 HDSFLSRPEA VFGATGGSLG HGSGNKDGMS ASRNCSKNSK ENMPPVIILD

451 DDDLPPLDDI TQHQPAFHIR KETSSPVVLA KPGDSCFSGG LLGPDGNYWH

501 LGKWCKRK

B

1 MASLVSKSSK PSKPTPQSSS APPSRSSSSS SSLSTHFAMI ELKQRILTSI 51 SKLSDRDTHQ IAVEDLEKII QTLSNDGVSM LINCLYDASN DPKPAVKKET 101 LRLLPTVCAS HGDSAATHLT KIIGNIVKRL KDSDSGVRDA CRDAIGSLSS 151 LYLKGEAESG GIGSVVALFV KPLFEAMNEN SKTVQSGAAL CMAKVVECAS 201 DPPVLSFQK工 CPRICKYLNN PHFVAKASLL PVVSSLSQVG AIAPQNLEPL 251 LQTIHECLSN TDWATRKAAA DTLSALALNS SNLVAGGATS TLTVLEASRF 301 DKIKPVRDSM LEALQHWKKI AGKEDGATDD QKTSCIDGES SESAGSSEKD 351 LRNAVGILKK RGPALSDRKL NPEFFQKLEE RSSNDLPVEV VVPRQCLNAS

401 NTPTEVESVS EKAETGQRTM RKSQIDTRYS NTESQTSGVS GREHDTVDEG 451 DLNQREQSSY RTGFAKNAGP PEGFMANKGN WLAIQRQLLL LERQQAHLTN 501 MLQDFMGGSH GSMVALENRV RGLERVVEDM AHDLSLSAGR RGGAFTARFD 551 ESLNRALGKY NSFHDYSSTK LGRGSEGSIP FGERFVPSDG NSSGVRGRSP 601 PRRSDNPDAW DFHSYGKYGQ SGSRRGIGGG PMDARSSKLE NEIDQVGTRR 651 GWAKGTGPVR FGEGPSARSI WQASKDEATL EAIRVAGDDN GTARGTRVAI 701 PELEAEALTD DNNMQERDPV WTSWTNAMDA FSVGDMDSAF SEVLSTGDDF 751 LLVKLMDRSG PVIDQLSNEV ASEALHAVAQ FLLEPNLTDI CLSWVQQLLE 801 IVIENGPEVV DLPMEVKKEL LLNLNEISSS VDLPEDWEGA TPEQLLLQLA 851 SAWDIDLQEL EK

Fig 3. The deduced amino acid sequences of A, HIP1 and B, HIP2. The arrowheads indicate the starting positions of the original HIP clones isolated from the cDNA library using the yeast two-hybrid system. In the HIP1 sequence, the predicted RING-H2 domain is underlined with a solid line. The consensus zinc-binding ligands in the RING-H2 domain are highlighted in bold. The predicted coiled-coil domains are dash-underlined and the conserved leucine residues are double-underlined. A putative ATP/GTP-binding site (P-loop) in the beginning of the protein is formed by amino acids 3 to 10 (underlined with an undulated line). 
mation was carried out by the lithium acetate method (Schiestl and Gietz 1989). Transformants were selected by plating on synthetic minimal media, on which selection was based on lacking amino acids leucine, tryptophan, and histidine and were grown for three to five days at $30^{\circ} \mathrm{C}$.

\section{Yeast $\beta$-galactosidase activity assays.}

The expression of the $\beta$-galactosidase reporter gene was evaluated qualitatively by filter assays. Several colonies of each transformation were transferred onto Whatman filter and were frozen in liquid nitrogen for $10 \mathrm{~s}$. Subsequently, the filter was placed onto another filter presoaked with $\mathrm{Z}$ buffer $(60 \mathrm{mM}$ $\mathrm{Na}_{2} \mathrm{HPO}_{4}, 40 \mathrm{mM} \mathrm{NaH}{ }_{2} \mathrm{PO}_{4}, 10 \mathrm{mM} \mathrm{KCl}, 1 \mathrm{mM} \mathrm{MgSO}$, pH 7.0, $50 \mathrm{mM} \beta$-mercaptoethanol) containing X-Gal (0.3 mg per $\mathrm{ml})$. The color reactions were observed for 1 to $12 \mathrm{~h}$.

Quantitative $\beta$-galactosidase activity assays were carried out on liquid cultures. For each test, cells were collected from $1 \mathrm{ml}$ of culture grown to an approximate optical density at $600 \mathrm{~nm}$ $\left(\mathrm{OD}_{600}\right)$ of 1 , were resuspended in $50 \mu \mathrm{l}$ of cell lysis buffer $(50$ mM Tris- $\mathrm{HCl}, \mathrm{pH} 8.0,5 \mathrm{mM}$ EDTA, $0.4 \mathrm{M} \mathrm{NaCl}, 100 \mathrm{U}$ Trasylol per $\mathrm{ml}, 1 \% \mathrm{NP}-40$ ) supplemented with $2 \mathrm{mM}$ phenylmethylsulfonyl fluoride (PMSF) and 1\% Triton X-100, and were vortexed for $6 \mathrm{~min}$ at $4^{\circ} \mathrm{C}$, after adding $0.3 \mathrm{~g}$ of acidwashed glass beads $(0.5 \mathrm{~mm})$ (Sigma, St. Louis). Z-buffer (650 $\mu \mathrm{l})$ was added to the cell lysate, and the mixture was incubated with $160 \mu \mathrm{l}$ of $o$-nitrophenyl- $\beta$-D-galactopyranoside solution (4 $\mathrm{mg}$ per $\mathrm{ml} \mathrm{Z}$ buffer) for 10 to $60 \mathrm{~min}$. After brief centrifugation, the supernatant was measured at $\mathrm{OD}_{420}$. The $\beta$-galactosidase units were calculated using the formula (Miller 1972): $\mathrm{OD}_{420} \times 1000 /\left(\mathrm{OD}_{600} \times t \times v\right)$, when $\mathrm{OD}_{420}$ is the absorbance of the reaction mixture, $\mathrm{OD}_{600}$ is the cell density of the culture, $t$ is the reaction time in $\mathrm{min}$, and $v$ is the volume (in $\mathrm{ml}$ ) of culture used for the assay.

\section{Recombinant protein expression in $E$. coli.}

To obtain fusion proteins with MBP, the EcoRI-SalI fragments of cDNA clones of Hip1 and Hip2 that cover the coding regions and $3^{\prime}$ noncoding sequences were moved from the corresponding yeast plasmids into EcoRI/SalI linearized vector pMal-cR1 (New England Biolabs, Beverly, MA, U.S.A.), resulting in pMBP-HIP1 and pMBP-HIP2. The recombinant plasmids and the empty vector (pMBP) were transformed into E. coli expression strain BL21 (Novagen, Madison, WI, U.S.A.). Expression of pMBP led to synthesis of MBP fused with the $\alpha$ fragment of $\beta$-galactosidase, and the product (designated as MBP) was used as negative control in in vitro assays. Expression of the MBP-fusion proteins was carried out as described (Merits et al. 1999), and the cells were lysed in binding buffer (50 mM Na-phosphate, pH 7.0, $500 \mathrm{mM} \mathrm{NaCl}, 10 \mathrm{mM}$ $\beta$-mercaptoethanol, 1.0 mM PMSF). The cell lysates were clarified by centrifugation for $10 \mathrm{~min}$ at $12,000 \times \mathrm{g}$, and the supernatant containing soluble proteins was used directly for in vitro binding assays.

\section{In vitro translation.}

To obtain ${ }^{35} \mathrm{~S}$-labeled HCpro, the coding sequence was cloned into pcDNA3 (Promega, Madison, WI, U.S.A.) in favorable Kozak context. The in vitro translation was carried out with the TnT Coupled Transcription/Translation System according to the instructions of the manufacturer (Promega). The translation mixture was used directly for the pull-down assays.

\section{In vitro binding assay.}

The pull-down assays and modified ELISA were carried out. For the pull-down assays, $200 \mu \mathrm{l}$ supernatant of $E$. coli cell lysate containing MBP or MBP-fusion proteins were mixed with $10 \mu \mathrm{l}$ of in vitro translation product containing ${ }^{35} \mathrm{~S}$-labeled PVA
HCpro. The mixture was incubated on a rotating wheel at $4^{\circ} \mathrm{C}$ for $2 \mathrm{~h}$ and, subsequently, $50 \mu \mathrm{l}$ of $50 \%$ amylose resin (New England Biolabs) was added. After incubation for another $2 \mathrm{~h}$, the resin was precipitated by centrifugation at $500 \times g$ for 5 min and was washed three times in the binding buffer. The resin was finally resuspended in $30 \mu \mathrm{l}$ Laemli buffer and boiled for $5 \mathrm{~min}$. The protein samples were separated by the standard sodium dodecyl sulphate-polyacrylamide gel electrophoresis (SDS-PAGE). The autoradiographic images were visualized by using the Fuji BAS-1500 PhosphoImager (Fujifilm Co., Tokyo).

For the ELISA assays, the plates were coated with recombinant PVA HCpro (Merits et al. 1999) at $2 \mu \mathrm{g}$ per $\mathrm{ml}$ and were blocked with $3 \%$ BSA and 3\% skim milk in phosphate-buffed saline (PBS). The protein samples containing MBP or MBP fusions (as described above) were diluted at 1:20 in PBS and $0.5 \%$ Tween-20 and were added to the plates for binding to HCpro. The binding reaction was detected using polyclonal rabbit antibodies specific to MBP and secondary alkaline phosphatase-conjugated, polyclonal anti-rabbit goat antibodies (New England Biolabs).

\section{Southern blot analysis.}

Total DNA was isolated from young potato leaves according to the procedures of Doyle and Doyle (1988). The probes were
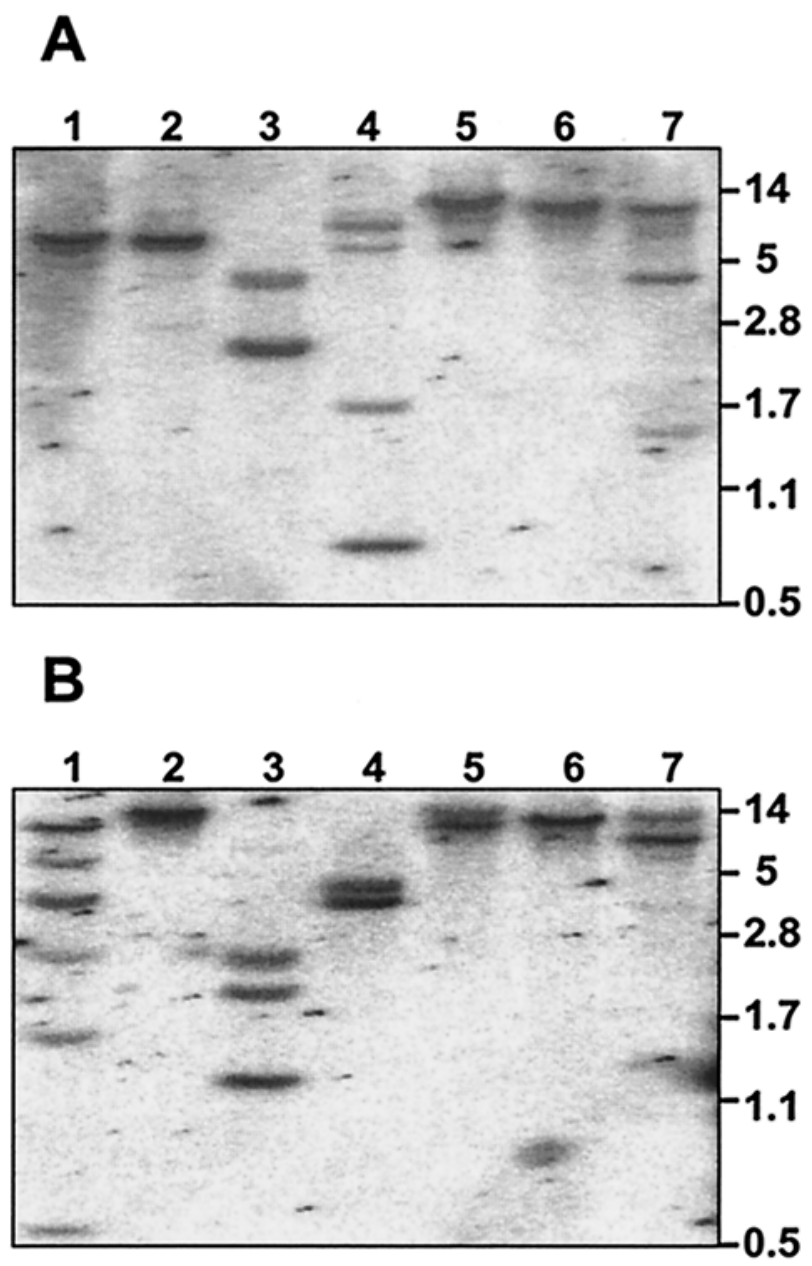

Fig. 4. Southern blot analysis shows that A, Hip1 and B, Hip2 are single copy genes in the potato genome. Seven different restriction enzymes were used to digest potato genomic DNA: 1, EcoRI; 2, EcoRV; 3, HindIII; 4, XbaI; 5, ApaI; 6, SacI; and 7, KpnI. The blots were detected with the probes generated from full-length cDNAs of Hip1 and Hip2. The DNA size markers in kilobases $(\mathrm{kb})$ are shown to the right. 
synthesized using the Rediprime II DNA Labeling System (Amersham Biosciences, Little Chalfont, England, U.K.). Southern blot analysis was carried out according to standard protocols (Sambrook et al. 1989), and the blots were washed under stringent conditions $(0.5 \times \mathrm{SSC}(1 \times \mathrm{SSC}$ is $0.15 \mathrm{M} \mathrm{NaCl}$ plus $0.015 \mathrm{M}$ sodium citrate), $0.1 \% \mathrm{SDS}$ at $60^{\circ} \mathrm{C}$ ).

\section{ACKNOWLEDGMENTS}

We thank K. Bengtsson for excellent technical assistance, V. Sorri and S. Vidal for providing the potato cDNA library, and S. M. Hollenberg (Vollum Institute, Portland, OR, U.S.A.) for providing yeast two-hybrid vectors and strains. This study was financially supported by grants from the European Union (\#BIO4-CT97-2356) and Formas, Sweden (\#22.0/2001-1223) to J. Valkonen. D. Guo is currently supported by the China NSFC grant 30270313. M. Saarma is a Fellow of Biocentrum Helsinki.

\section{LITERATURE CITED}

Anandalakshmi, R., Pruss, G. J., Ge, X., Marathe, R., Mallory, A. C. Smith, T. H., and Vance V. B. 1998. A viral suppressor of gene silencing in plants. Proc. Natl. Acad. Sci. U.S.A. 95:13079-13084.

Anandalakshmi, R., Marathe, R., Ge, X., Herr, J. M., Jr., Mau, C., Mallory, A., Pruss, G., Bowman, L., and Vance, V. B. 2000. A calmodulin-related protein that suppresses posttranscriptional gene silencing in plants. Science 290:142-144.

Atreya, C. D., and Pirone, T. P. 1993. Mutational analysis of the helper component-proteinase gene of a potyvirus: Effects of amino acid substitutions, deletions, and gene replacement on virulence and aphid transmissibility. Proc. Natl. Acad. Sci. U.S.A. 90:11919-11923.

Brigneti, G., Voinnet, O., Li, W. X., Ji, L. H., Ding, S. W., and Baulcombe, D. C. 1998. Viral pathogenicity determinants are suppressors of transgene silencing in Nicotiana benthamiana. EMBO (Eur. Mol. Biol. Organ.) J. 17:6739-6746.

Carrington, J. C., Cary, S. M., Parks, T. D., and Dougherty, W. G. 1989. A second proteinase encoded by a plant potyvirus genome. EMBO (Eur. Mol. Biol. Organ.) J. 8:365-370.

Cronin, S., Verchot, J., Haldeman-Cahill, R., Schaad, M. C., and Carrington, J. C. 1995. Long-distance movement factor: A transport function of the potyvirus helper component proteinase. Plant Cell 7:549-559.

Dolja, V. V., Herndon, K. L., Pirone, T. P., and Carrington, J. C. 1993. Spontaneous mutagenesis of a plant potyvirus genome after insertion of a foreign gene. J. Virol. 67:5968-5975.

Doyle, J. J., and Doyle, J. L. 1988. Isolation of plant DNA from fresh tissue. Focus 12:13-15

Freemont, P. S. 2000. RING for destruction? Curr. Biol. 10:84-87.

Guo, D., Merits, A., and Saarma, M. 1999. Self-association and mapping of interaction domains of helper component proteinase of potato A potyvirus. J. Gen. Virol. 80:1127-1131.

Hämäläinen, J. H., Kekarainen, T., Gebhardt, C., Watanabe, K. N., and Valkonen, J. P. T. 2000. Recessive and dominant genes interfere with the vascular transport of Potato virus $A$ in diploid potatoes. Mol. Plant-Microbe Interact. 13:402-412.

Hollenberg, S. M., Sternglanz, R., Cheng, P. F., and Weintraub, H. 1995. Identification of a new family of tissue-specific basic helix-loop-helix proteins with a two-hybrid system. Mol. Cell. Biol. 15:3813-3822.

Jensen, R. B., Jensen, K. L., Jespersen, H. M., and Skriver, K. 1998. Widespread occurrence of a highly conserved RING-H2 zinc finger motif in the model plant Arabidopsis thaliana. FEBS (Fed. Eur. Biochem. Soc.) Lett. 436:283-287.

Karlin, S., and Altschul, S. F. 1990. Methods for assessing the statistical significance of molecular sequence features by using general scoring schemes. Proc. Natl. Acad. Sci. U.S.A. 87:2264-2268.

Kasschau, K. D., and Carrington, J. C. 1995. Requirement for HCpro processing during genome amplification of tobacco etch potyvirus. Virology 209:268-273.

Kasschau, K. D., and Carrington, J. C. 1998. A counterdefensive strategy of plant viruses: Suppression of posttranscriptional gene silencing. Cell 95:461-70.

Kasschau, K. D., Cronin, S., and Carrington, J. C. 1997. Genome amplification and long-distance movement functions associated with the central domain of tobacco etch potyvirus helper component-proteinase.
Virology 228:251-262.

Kjeldgaard, M., Nyborg, J., and Clark, B. F. 1996. The GTP binding motif: Variations on a theme. FASEB (Fed. Am. Soc. Exp. Biol.) J. 10:1347-1368.

Landschulz, W. H., Johnson, P. F., and McKnight, S. L. 1988. The leucine zipper: A hypothetical structure common to a new class of DNA binding proteins. Science 240:1759-1764.

Lee, S. Y., Lee, S. Y., and Choi, Y. 1997. TRAF-interacting protein (TRIP): A novel component of the tumor necrosis factor receptor (TNFR)- and CD30-TRAF signaling complexes that inhibits TRAF2mediated NF-kappaB activation. J. Exp. Med. 185:1275-1285.

Maia, I. G., and Bernardi, F. 1996. Nucleic acid-binding properties of a bacterially expressed potato virus $\mathrm{Y}$ helper component-proteinase. J. Gen. Virol. 77:869-877.

Maia, I. G., Haenni, A. L., and Bernardi, F. 1996. Potyviral HCpro: A multifunctional protein. J. Gen. Virol. 77:1335-1341.

McLachlan, A. D., and Karn, J. 1982. Periodic charge distributions in the myosin rod amino acid sequence match cross-bridge spacings in muscle. Nature 299:226-231.

Merits, A., Guo, D., and Saarma, M. 1998. VPg, coat protein and five non-structural proteins of potato A potyvirus bind RNA in sequenceunspecific manner. J. Gen. Virol. 79:3123-3127.

Merits, A., Guo, D., Jarvekulg, L., and Saarma, M. 1999. Biochemical and genetic evidence for interactions between potato A potyvirus-encoded proteins $\mathrm{P} 1$ and $\mathrm{P} 3$ and proteins of the putative replication complex. Virology 263:15-22.

Miller, J. H. 1972. Experiments in Molecular Genetics. Cold Spring Harbor Laboratory Press, Cold Spring Harbor, NY, U.S.A.

Pirone, T. P., and Blanc, S. 1996. Helper-dependent vector transmission of plant viruses. Ann. Rev. Phytopathol. 34:227-247.

Pruss, G., Ge, X., Shi, X. M., Carrington, J. C., and Vance, V. B. 1997. Plant viral synergism: The potyviral genome encodes a broad-range pathogenicity enhancer that transactivates replication of heterologous viruses. Plant Cell 9:859-868.

Puurand, Ü., Valkonen, J. P. T., Mäkinen, K., Rabenstein, F., and Saarma, M. 1996. Infectious in vitro transcripts from cloned cDNA of the potato A potyvirus. Virus Res. 40:135-140.

Ratcliff, F., Harrison, B. D., and Baulcombe, D. C. 1997. A similarity between viral defense and gene silencing in plants. Science 276:15581560 .

Riechmann, J. L., Lain, S., and Garcia, J. A. 1992. Highlights and prospects of the potyvirus molecular biology. J. Gen. Virol. 73:1-16.

Rojas, M. R., Zerbini, F. M., Allison, R. F., Gilbertson, R. L., and Lucas, W. J. 1997. Capsid protein and helper component-proteinase function as potyvirus cell-to-cell movement proteins. Virology 237:283-295.

Sambrook, J., Fritsch, E. F., and Maniatis, T. 1989. Molecular Cloning: A Laboratory Manual. Cold Spring Harbor Laboratory Press. Cold Spring Harbor, NY, U.S.A.

Saurin, A. J., Borden, K. L., Boddy, M. N., and Freemont, P. S. 1996. Does this have a familiar RING? Trends Biochem. Sci. 21:208-214.

Savenkov, E.I., and Valkonen, J. P. T. 2001. Potyviral helper componentproteinase expressed in transgenic plants enhances titers of Potato leaf roll virus but does not alleviate its phloem-limitation. Virology 283:285-293

Savenkov, E. I., and Valkonen, J. P. T. 2002. Silencing of a viral RNA silencing suppressor in transgenic plants. J. Gen. Virol. 83:2325-2335.

Schiestl, R. H., and Gietz, R. D. 1989. High efficiency transformation of intact yeast cells using single stranded nucleic acids as a carrier. Curr. Genet. 16:339-346.

Shi, X. M., Miller, H., Verchot, J., Carrington, J. C., and Vance, V. B. 1997. Mutations in the region encoding the central domain of helper component-proteinase (HCpro) eliminate potato virus X/potyviral synergism. Virology 231:35-42.

Shukla, D. D., Ward, C. W., and Brunt, A. A. 1994. The Potyviridae. CAB International, Wallingford, U.K.

Sorri, V. A., Watanabe, K. N., and Valkonen, J. P. T. 1999. Predicted kinase 3 a motif of a resistance gene analogue as a unique marker for potyvirus resistance. Theor. Appl. Genet. 99:164-170.

Verwoerd, T. C., Dekker, B. M., and Hoekema, A. 1989. A small-scale procedure for the rapid isolation of plant RNAs. Nucleic Acids Res. 17:2362.

Yelina, N. E., Savenkov, E. I., Solovyev, A. G., Morozov, S. Y., and Valkonen, J. P. T. 2002. Long distance movement, virulence, and RNA silencing suppression controlled by a single protein in hordei- and potyviruses: Complementary functions between virus families. J. Virol. 76:12981-12991. 